\title{
Research and Application of a Proppant Transport Experimental Device for Complex Fractures in the Unconventional Reservoir
}

\author{
Huan Peng $(\mathbb{D}$, Yu Fan, Junliang Peng, Huifen Han, Xinping Gao, Liang Wang, Xinghao Gou, \\ Yuelin Yin, and Yuchao Zhou
}

Southwest Oil and Gas Field Company of Petro China Co. Ltd., Engineering Technology Research Institute, No. 25, Xiaoguanmiao Back Street, Qingyang District, Chengdu, Sichuan CN 610017, China

Correspondence should be addressed to Huan Peng; 282600120@qq.com

Received 10 November 2021; Revised 11 December 2021; Accepted 23 December 2021; Published 18 January 2022

Academic Editor: Zhiming Chen

Copyright (c) 2022 Huan Peng et al. This is an open access article distributed under the Creative Commons Attribution License, which permits unrestricted use, distribution, and reproduction in any medium, provided the original work is properly cited.

\begin{abstract}
Due to the brittleness of the shale and tight reservoir and the development of natural fractures and horizontal beddings, complex fractures will be built by shear slip and tensile failure during multistaged horizontal well fracturing. Whether proppant can enter complex fractures and form effective support in main fractures and branch fractures determines conductivity of the complex fracture and stimulation effect of multistaged horizontal well fracturing. By means of discretization of disordered complex fractures, the orthogonal three-dimensional physical model of complex fractures is obtained and the complex fracture experimental device for simulating fracture complexity is developed and a complete set of proppant transport characteristic experimental device in unconventional reservoir complex fractures is formed. Combined with field parameters and lab experiments, the influence of proppant performance parameters and discharge capacity to proppant transport characteristics in complex fractures of the unconventional reservoir is studied. And on the basis of experimental results and analysis, the sensitivity analysis method is applied to analyze the influence degree of proppant transport characteristics in complex fractures of the shale or tight sandstone reservoir. The sensitivity order of influence factors is fracture morphology, proppant performance, liquid viscosity, displacement, and proppant concentration. The experimental device and research results can provide strong experimental support for the optimisation of shale or tight sandstone fracturing materials and field parameters.
\end{abstract}

\section{Introduction}

To access large shales or tight sandstone gas, multistage fracking is typically utilized, which is repeatedly used in each horizontal well as many as 20 times [1-9]. An unconventional reservoir (shale or tight sandstone) is characterized by the brittleness, natural fractures, and horizontal bedding developed. Shear slip and tensile failure are easy to occur during fracturing. Artificial fractures are complex fractures instead of a single symmetrical wing fracture as shown in Figure 1; the main fractures and branch fractures in complex fractures are orthogonal and interconnected. During fracturing operation, whether proppant can enter complex fractures and form effective support in main fractures and branch fractures determines the conductivity of complex fractures and the stimulation effect of multistaged horizontal well fracturing [10]. Therefore, the transport of proppant in complex fractures plays an important role in the success of multistaged horizontal well fracturing.

At present, the research of proppant transport in the fracture is mainly a theoretical aspect. Lab engineering simulation and evaluation experiments are rarely carried out, and most of them are single fractures, and the complexity of the fracture is limited [11-22].

Therefore, it is necessary to master the formation mechanism, morphological analysis, and characterization of complex fractures in the unconventional reservoir (shale or tight sandstone) and develop an experimental device that can effectively simulate complex fractures. Combined with field parameters, lab experimental research is carried out to quantitatively study the influence of displacement, proppant/fluid type, fracture morphology, and other factors on proppant transport in complex fractures, so as to provide strong 


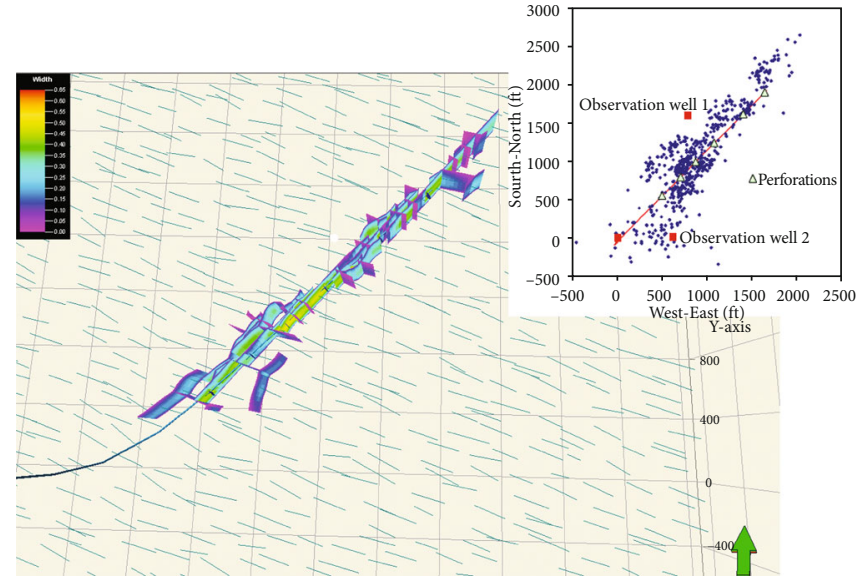

(a)

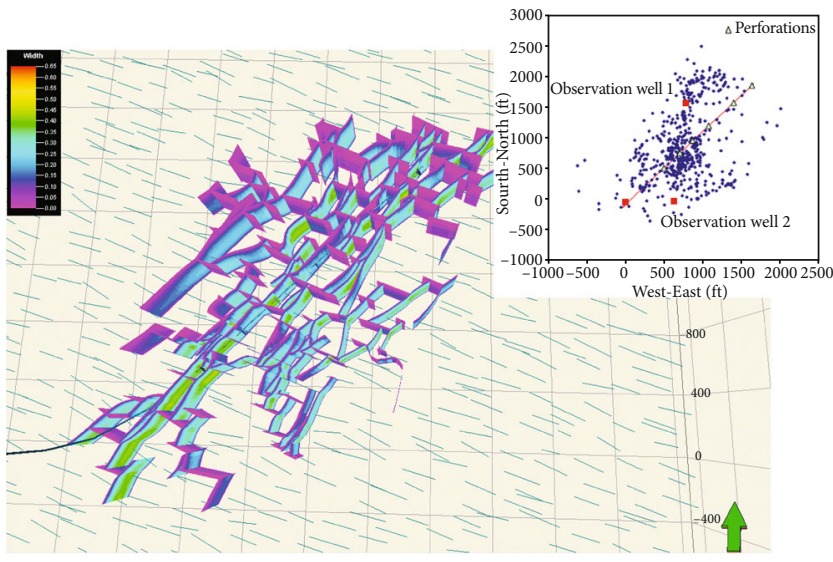

(b)

FIGURE 1: Schematic diagram of the single symmetrical wing fracture with gel fracturing (a) and complex fractures with slickwater fracturing (b) $[10]$.

technical support when optimizing proppant and field parameters for the unconventional reservoir (shale or tight sandstone).

\section{Development of the Experimental Device}

2.1. Design Principle. Multistaged horizontal well fracturing is easily capable of producing branch fractures and eventually forming complex fractures. In order to study the transport characteristics of proppant in complex fractures, hydraulic fractures and natural fractures intersect and combine in a certain way to form fractures with different structures [14]. Finally, the disordered complex fractures are discretized to obtain an orthogonal three-dimensional physical model of complex fractures, as shown in Figure 2.

2.2. Device Design. Based on the orthogonal three-dimensional physical model of complex fractures and in order to observe the transport characteristics of proppant in the fracture, $4 \times$ $4 \times 4$ pieces of plexiglass are used to form $3 \times 3 \times 3$ vertical and horizontal cross complex fractures, as shown in Figure 3.

There are 4 layers of the complex fracture device with 16 pieces of plexiglass in each layer. Fractures are formed between plexiglass. Different thickness gaskets are used to adjust the width of the plexiglass, and layers are assembled from bottom to top, as shown in Figure 4.During the assembly process, different fracture models can be obtained by reserving the fracture in different plexiglass. Some different types of fracture models are shown in Figure 5.

2.3. Device Parameters. On the basis of the complex fracture device, the fluid tank, screw pump, flowmeter, sand storage tank, sand supply pump, liquid circulation pump, image, and data acquisition are connected, and finally, the experimental device of proppant transport characteristics in the complex fracture of the unconventional reservoir is formed. The flow chart and the physical diagram are shown in Figures 6 and 7, respectively.

The functional parameters of the experimental device are shown in Table 1. The highlight of the device is that there are 27 fracture nodes. As the experimental requirements are changing, the direction and width of fractures can be adjusted at different nodes, so as to obtain the complex fractures with different geometry and widths, which is helpful to complete the simulation experiment of proppant transport characteristics in complex fractures.

\section{Experimental Methods}

3.1. Determination of Experimental Parameters. According to the principle of Reynolds similarity [14], the field displacement of multistaged horizontal well fracturing is converted into the lab experimental displacement and calculation formula (1) is as follows:

$$
v_{e}=\frac{v_{f}}{h_{f} \times w_{f} \times 2} \times\left(h_{e} \times w_{e}\right),
$$

where $v_{e}$ means lab experimental displacement, $\mathrm{m}^{3} / \mathrm{min}, v_{f}$ is field displacement, $\mathrm{m}^{3} / \mathrm{min}, h_{f}$ is the height of the artificial fracture, $\mathrm{m}, w_{f}$ is the width of artificial fracture, $\mathrm{mm}, h_{e}$ is the height of the fracture in the complex fracture experimental device, $\mathrm{m}$, and $w_{e}$ is the width of the fracture in the complex fracture experimental device, $\mathrm{mm}$.

3.2. Record of the Experiment Process. The highspeed video camera in the data acquisition and control system is used to record the experimental process and record the transport characteristics of proppant in the complex fracture experimental device under different experimental conditions, as shown in Figure 8. Some experimental results are shown in Figure 9.

3.3. Experimental Scheme. In order to study the influence of proppant performance, displacement, sand concentration, liquid viscosity, and fracture morphology on proppant transport characteristics in complex fractures, the experimental scheme design is shown in Table 2. 

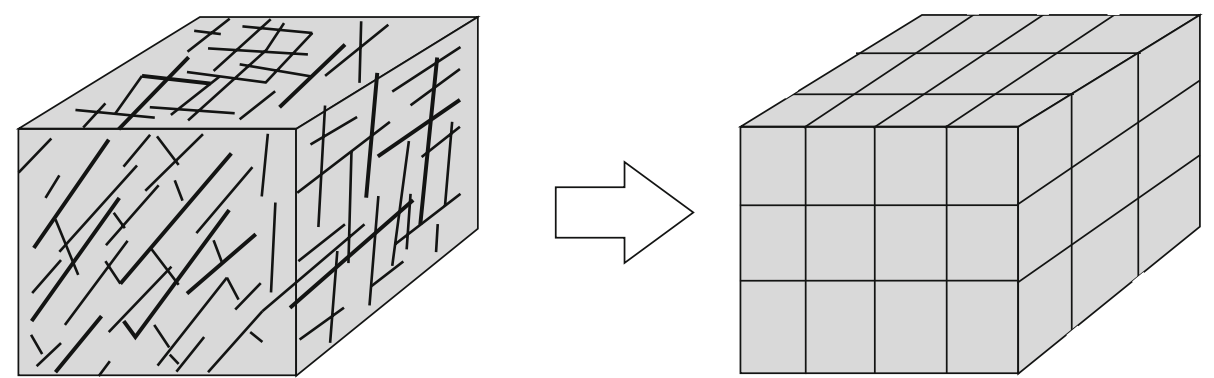

FIGURE 2: Schematic diagram of the discretized complex fracture model [14].

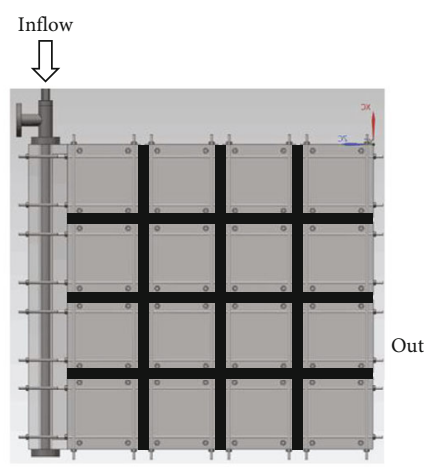

Front view

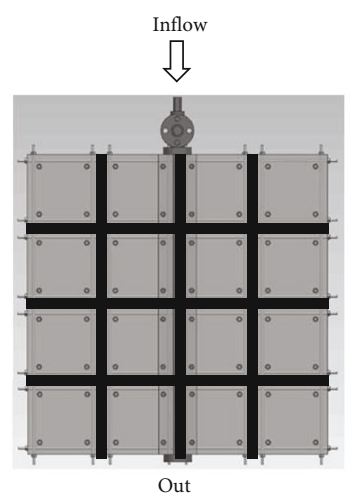

Side view

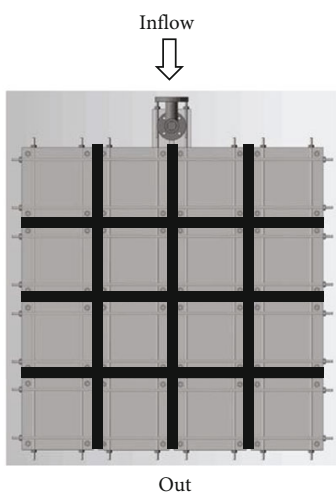

Top view

FIgURE 3: Schematic diagram of the complex fracture device design.

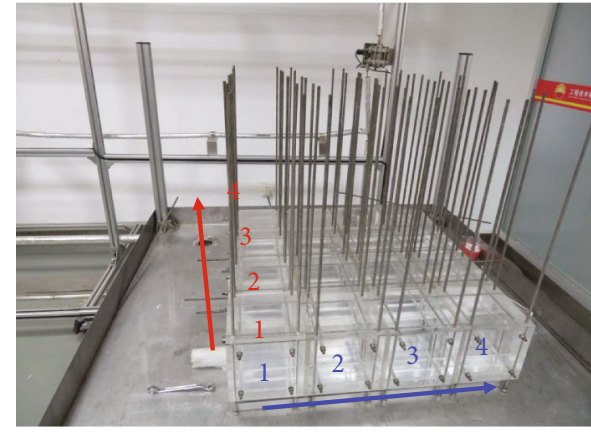

The first floor of complex fracture device

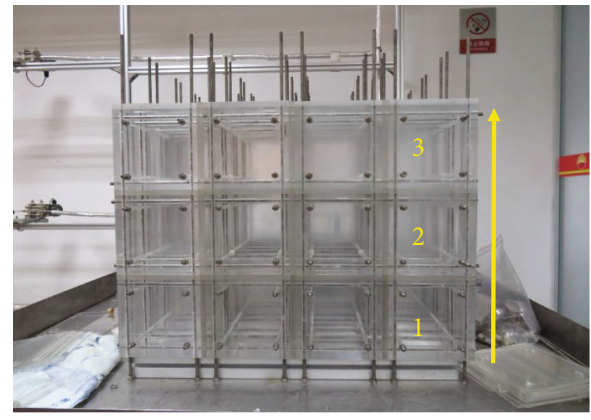

The third floor of complex fracture device

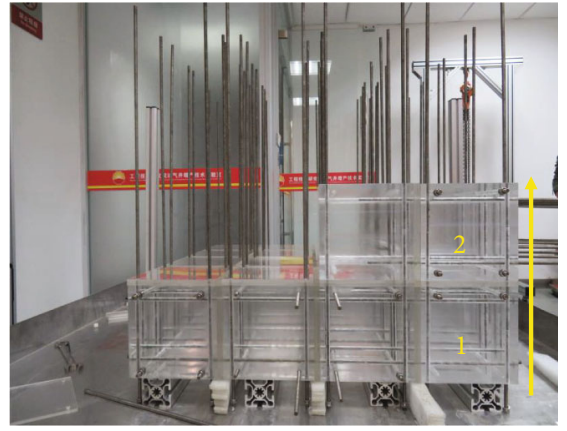

The second floor of complex fracture device

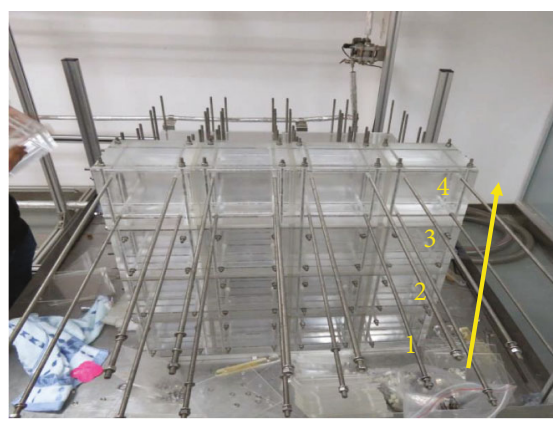

The fourth floor of complex fracture device

FIgURe 4: Assembly process of the complex fracture device. 


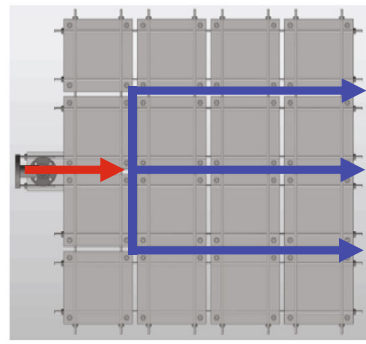

$1+\mathrm{E}$

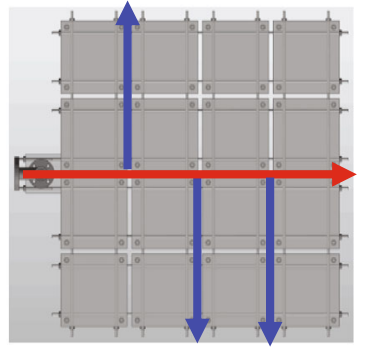

TF

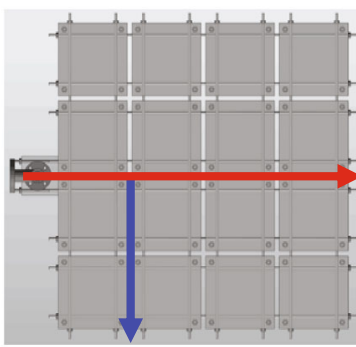

$\mathrm{T}$

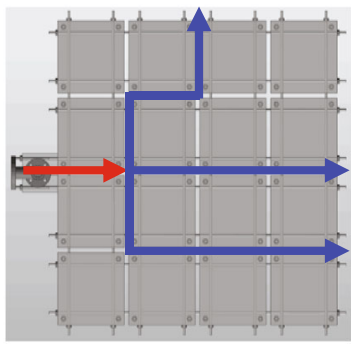

$1+\mathrm{X} 1$

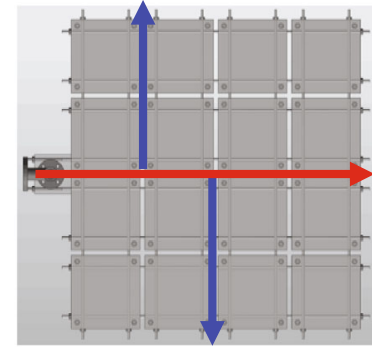

Double T

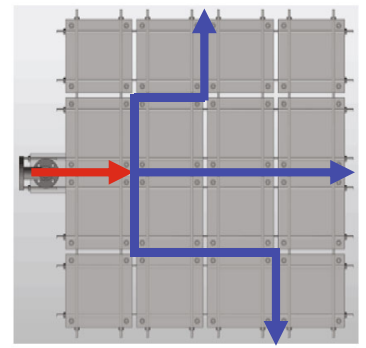

$1+\mathrm{X} 2$

Figure 5: Different types of fractures models.

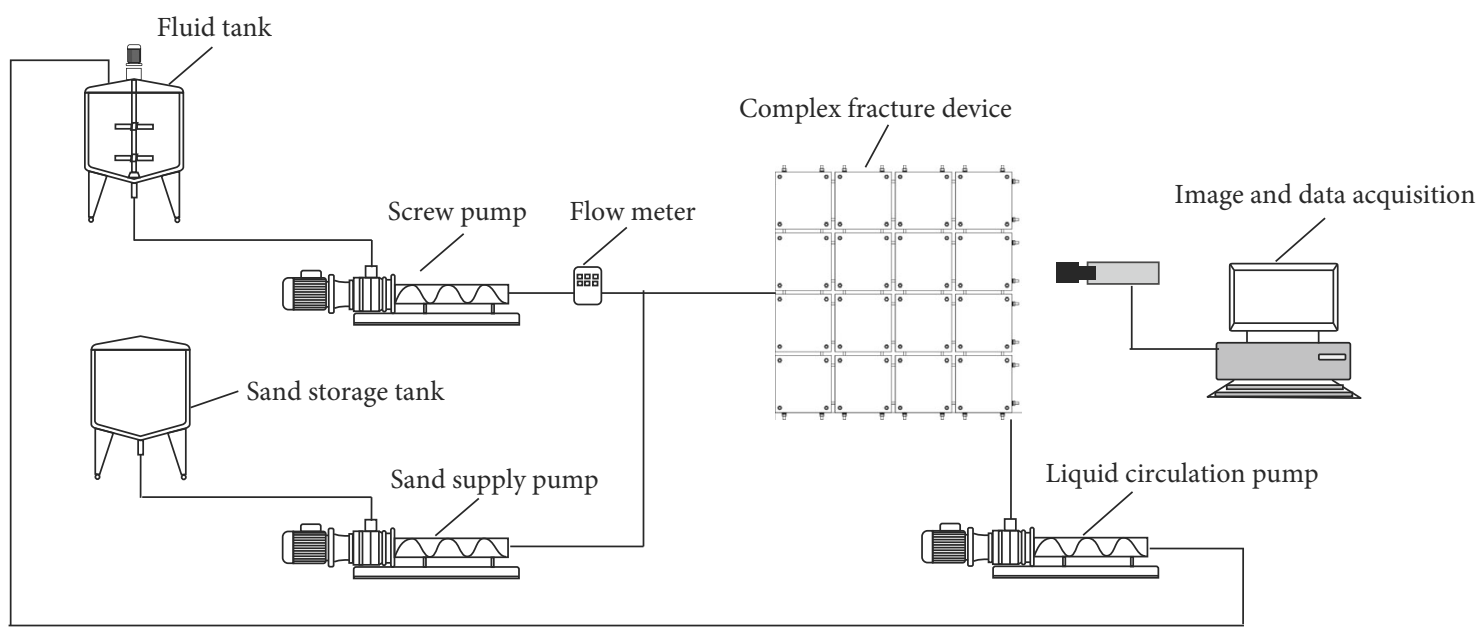

Figure 6: The flow chart of the experimental device of proppant transport characteristics in complex fractures.

\section{Experimental Results and Analysis}

4.1. The Influence of the Proppant Performance to Transport. The characteristics of transport in the main fracture are shown in Figure 10(a). The balance heights (proppant vertical transport distance) of 40/70 mesh ceramsite, 50/100 mesh ceramsite, and 70/140 mesh ceramsite are $120 \mathrm{~mm}, 100 \mathrm{~mm}$, and $92 \mathrm{~mm}$, respectively. By comparing 70/140 mesh ceramsite with $70 / 140$ mesh quartz sand, 70/140 mesh quartz sand is relatively consistent in the main fracture and the balance height is $75 \mathrm{~mm}$.

The characteristics of transport in the branch fractures are shown in Figure 10(b). The balance heights of 40/70 mesh ceramsite, 50/100 mesh ceramsite, 70/140 mesh ceramsite, and 70/140 mesh quartz sand are $32 \mathrm{~mm}, 114 \mathrm{~mm}, 100 \mathrm{~mm}$, and $82 \mathrm{~mm}$, respectively, and the front edge distances (proppant horizontal transport distances) are $371 \mathrm{~mm}, 448 \mathrm{~mm}$, $525 \mathrm{~mm}$, and $600 \mathrm{~mm}$, respectively.

The balance heights of the same proppant in the main fractures are longer than those in the branch fractures, and the slope of proppant dune is relatively smoother with the same proppant transport in the main fracture, which is caused by stronger scouring effect of liquid on the proppant dune.

During field operation, in order to form longer and effective proppant fractures, under the condition of satisfying the proppant strength, the proppant with small granularity and low density should be used as far as possible, so that the proppants can be transported further in the fractures. 


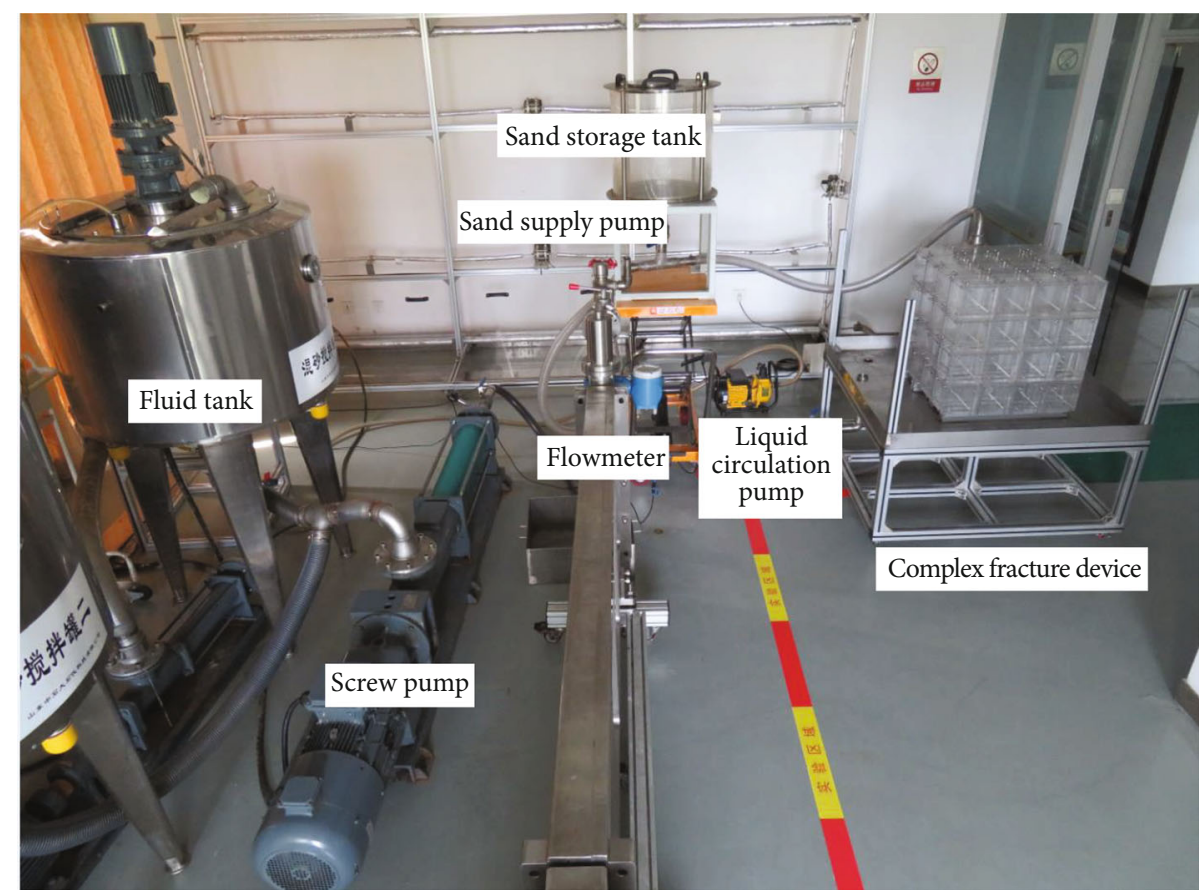

FIGURE 7: The overall appearance of the experimental device of proppant transport characteristics in complex fractures.

TABLE 1: Functional parameters of the proppant transport characteristic complex fracture experimental device.

\begin{tabular}{lc}
\hline Item & Parameter value \\
\hline Unit size of complex fracture device & $600 \mathrm{~mm}^{*} 600 \mathrm{~mm}^{*} 600 \mathrm{~mm}^{\circ}$ \\
The length and number of main fractures & $600 \mathrm{~mm}, 1 \mathrm{fracture}$ \\
The length and number of second fractures & $600 \mathrm{~mm}, 3 \mathrm{fractures}$ \\
The length and number of third fractures & $600 \mathrm{~mm}, 3 \mathrm{fractures}$ \\
Horizontal fractures & $600 \mathrm{~mm}, 3 \mathrm{fractures}$ \\
Fracture height & $150 \sim 600 \mathrm{~mm}$ \\
Fracture width & $1 \sim 10 \mathrm{~mm}$ \\
Fracture nodes & 27 \\
Maximum displacement & $200 \mathrm{~L} / \mathrm{min}$ \\
Pressure resistance & $1.2 \mathrm{MPa}$ \\
Suitable proppant types & Various proppant particles of 20 140 mesh \\
Suitable liquid type & Slickwater, linear gel \\
\hline
\end{tabular}

4.2. The Influence of Displacement to Transport. The transport characteristics in the main fracture are shown in Figure 11(a). When the experimental displacements are $12.5 \mathrm{~L} / \mathrm{min}, 15.0 \mathrm{~L} /$ $\mathrm{min}$, and $17.5 \mathrm{~L} / \mathrm{min}$, the balance heights of proppant in the main fractures are $120 \mathrm{~mm}, 111 \mathrm{~mm}$, and $100 \mathrm{~mm}$, respectively.

The transport characteristics in branch fractures are shown in Figure 11(b). When the experimental displacements are $12.5 \mathrm{~L} / \mathrm{min}, 15.0 \mathrm{~L} / \mathrm{min}$, and $17.5 \mathrm{~L} / \mathrm{min}$, the balance heights of the proppant in the branch fractures are $136 \mathrm{~mm}$, $128 \mathrm{~mm}$, and $106 \mathrm{~mm}$, respectively, and the front edge distances of the proppant in branch fractures are $401 \mathrm{~mm}$, $432 \mathrm{~mm}$, and $485 \mathrm{~mm}$, respectively.

By comparing the experimental results under the same displacement conditions, it is similar to the experimental results when the proppant performance is used as a variable. The transport characteristics in the main fracture are caused by the stronger scouring effect of the liquid on the proppant dune in the main fracture. The larger the displacement, the stronger the scouring effect, resulting in a longer balance stage of the proppant dune than the branch fractures, and the slope of the proppant dune is relatively flat.

During field operation, large displacement can make the proppant transport further in the complex fractures, which is beneficial in increasing the length of the proppant fractures, but will reduce the proppant concentration at the nearwellbore fractures. In order to maximize the near-wellbore fracture conductivity, the displacement should be reduced slowly step by step during the later stage, so as to cause 


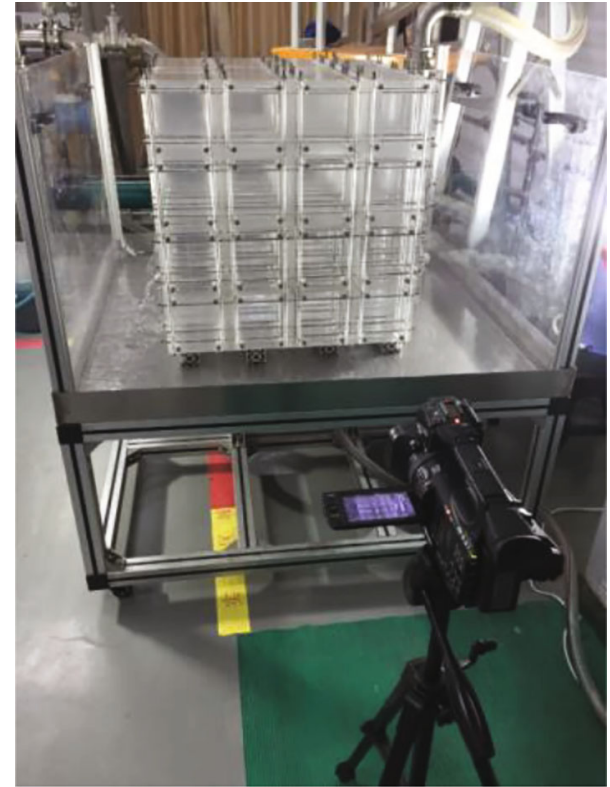

FIGURE 8: Highspeed video camera record proppant transport characteristics in complex fractures.

proppant settling near the wellbore and to increase the accumulation of the proppant at the near-wellbore fractures.

4.3. The Influence of Sand Concentration to Transport. The transport characteristics in the main fracture are shown in Figure 12 (a). When the sand concentrations are $150 \mathrm{~kg} / \mathrm{m}^{3}$, $200 \mathrm{~kg} / \mathrm{m}^{3}$, and $250 \mathrm{~kg} / \mathrm{m}^{3}$, the balanced heights of the proppant in the main fracture are $133 \mathrm{~mm}, 121 \mathrm{~mm}$, and $111 \mathrm{~mm}$, respectively.

The transport characteristics in the branch fractures are shown in Figure 12(b). When the sand concentrations are $150 \mathrm{~kg} / \mathrm{m}^{3}, 200 \mathrm{~kg} / \mathrm{m}^{3}$, and $250 \mathrm{~kg} / \mathrm{m}^{3}$, the balance heights of the proppant in the branch fractures are $136 \mathrm{~mm}$, $127 \mathrm{~mm}$, and $112 \mathrm{~mm}$, respectively, and the front edge distances of the proppant in the branch fractures are $422 \mathrm{~mm}$, $450 \mathrm{~mm}$, and $479 \mathrm{~mm}$, respectively.

By comparing the conditions of different sand concentrations, it is contrary to the experimental results when the displacement is used as a variable. At the same displacement, the balance stage of the proppant in the main fracture is longer than that in branch fractures and the slopes of the proppant are relatively flatter as a result of stronger scouring effect of the liquid and larger displacement.

During field operation, lower sand concentration is beneficial to the proppant transport further in the complex fractures, which is helpful to increase the length of the proppant fractures, but it will reduce the proppant concentration at the near-wellbore fractures. In order to maintain the nearwellbore fracture open, the sand concentration should increase slowly step by step during the later stage, so as to cause proppant settling at the near wellbore and to increase the accumulation of the proppant at the near wellbore and finally to provide low resistance to flow at the nearwellbore fracture.
4.4. The Influence of Fluid Viscosity to Transport. The transport characteristics in the main fracture are shown in Figure 13(a). When the viscosities of the fracturing fluid are $2 \mathrm{mPa} \cdot \mathrm{s}$ (slickwater) and $34 \mathrm{mPa} \cdot \mathrm{s}$ (linear gel), the balanced heights of proppant in the main fracture are $121 \mathrm{~mm}$ and $95 \mathrm{~mm}$, respectively.

The transport characteristics in branch fractures are shown in Figure 13(b). When the viscosities of fracturing fluid are $2 \mathrm{mPa} \cdot \mathrm{s}$ (slickwater) and $34 \mathrm{mPa} \cdot \mathrm{s}$ (linear gel), the balance heights of the proppant in branch fractures are $127 \mathrm{~mm}$ and $95 \mathrm{~mm}$, respectively, and the front edge distances of the proppant in branch fractures are $450 \mathrm{~mm}$ and $600 \mathrm{~mm}$, respectively.

By comparing different fluid viscosities, the experimental results are similar to the results when displacement is a variable. For different fracturing fluids, the balance stage of the proppant in the main fracture is longer and the slope of proppant dune is relatively gentled. As the viscosity increases, the transport capacity is relatively increased and the settlement speed of the proppant decreases, which has an influence on the formation and accumulation of the proppant dunes.

During field operation, the linear gel can appropriately increase the transport capacity, so that the proppant will be transported further to the complex fracture, which is beneficial in increasing the length of the proppant fracture, but it will reduce the proppant concentration at the nearwellbore fracture. Therefore, part of the linear gel slug is used to carry sand in the mid-term and slickwater in the later stage to ensure the length of the proppant complex fracture and the proppant concentration of at the nearwellbore fracture, so as to facilitate the flow from the reservoir through the fracture and to the wellbore.

4.5. The Influence of Fracture Geometry to Transport. The transport characteristics in the main fracture are shown in Figure 14(a). After the type " $1+\mathrm{E}$ " and type "T" fracture formed branch fractures at $150 \mathrm{~mm}$ in the horizontal direction, the balanced heights of proppant in the " $1+E$ " and type "T" main fracture are $116 \mathrm{~mm}$ and $102 \mathrm{~mm}$, respectively. After the type "double T" fracture formed branch fractures at $150 \mathrm{~mm}$ and $300 \mathrm{~mm}$ in the horizontal direction, the first and second balanced heights of proppant in the type "double $T^{\prime \prime}$ main fracture are $89 \mathrm{~mm}$ and $109 \mathrm{~mm}$, respectively. After the type "TF" fracture formed branch fractures at $150 \mathrm{~mm}$, $300 \mathrm{~mm}$, and $450 \mathrm{~mm}$ in the horizontal direction, the first, second, and third balanced heights of the proppant type "TF" main fracture are $77 \mathrm{~mm}, 97 \mathrm{~mm}$, and $104 \mathrm{~mm}$, respectively.

The transport characteristics in the branch fractures are shown in Figure 14(b). The heights of the proppant in the "T," "double T," and "TF" first branch fractures are $116 \mathrm{~mm}, 122 \mathrm{~mm}$, and $126 \mathrm{~mm}$, respectively. The heights of the proppant in the "double T" and "TF" second branch fracture are $98 \mathrm{~mm}$ and $87 \mathrm{~mm}$. The height of the proppant in the "TF" third branch fracture is $113 \mathrm{~mm}$.

By comparing the transport characteristics of proppants with different fracture geometry in the main fractures and branch fractures, as the fracture complexity gradually increases and the fluid in the fracture being multiply diverse, 

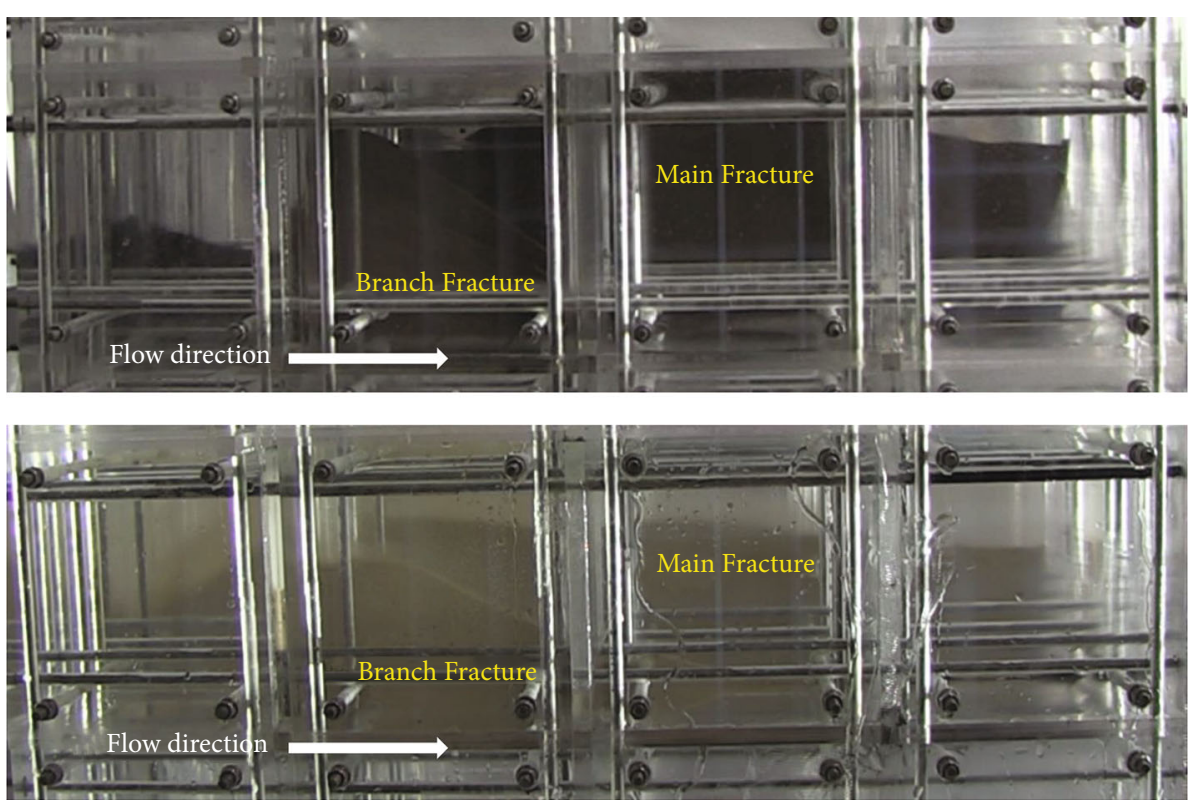

FIGURE 9: The different experimental results of proppant transport in complex fractures.

TABLE 2: Experimental scheme of proppant transport in complex fractures.

\begin{tabular}{|c|c|c|c|c|c|}
\hline Number & Proppant type & Experimental displacement (L/min) & Sand concentration $\left(\mathrm{kg} / \mathrm{m}^{3}\right)$ & $\begin{array}{l}\text { Liquid } \\
\text { type }\end{array}$ & $\begin{array}{c}\text { Fracture } \\
\text { morphology }\end{array}$ \\
\hline 1 & 40/70 mesh, ceramsite & 15 & 200 & Slickwater & $1+\mathrm{E}$ \\
\hline 2 & 50/100 mesh, ceramsite & 15 & 200 & Slickwater & $1+\mathrm{E}$ \\
\hline 3 & 70/140 mesh, ceramsite & 15 & 200 & Slickwater & $1+\mathrm{E}$ \\
\hline 4 & $\begin{array}{l}\text { 70/140 mesh, quartz } \\
\text { sand }\end{array}$ & 15 & 200 & Slickwater & $1+\mathrm{E}$ \\
\hline 5 & 40/70 mesh, ceramsite & 12.5 & 200 & Slickwater & $1+\mathrm{E}$ \\
\hline 6 & 40/70 mesh, ceramsite & 17.5 & 200 & Slickwater & $1+\mathrm{E}$ \\
\hline 7 & 40/70 mesh, ceramsite & 15 & 150 & Slickwater & $1+\mathrm{E}$ \\
\hline 8 & 40/70 mesh, ceramsite & 15 & 250 & Slickwater & $1+\mathrm{E}$ \\
\hline 9 & 40/70 mesh, ceramsite & 15 & 200 & Linear gel & $1+\mathrm{E}$ \\
\hline 10 & 40/70 mesh, ceramsite & 15 & 200 & Slickwater & $\mathrm{T}$ \\
\hline 11 & $40 / 70$ mesh, ceramsite & 15 & 200 & Slickwater & Double T \\
\hline 12 & $40 / 70$ mesh, ceramsite & 15 & 200 & Slickwater & $\mathrm{TF}$ \\
\hline
\end{tabular}

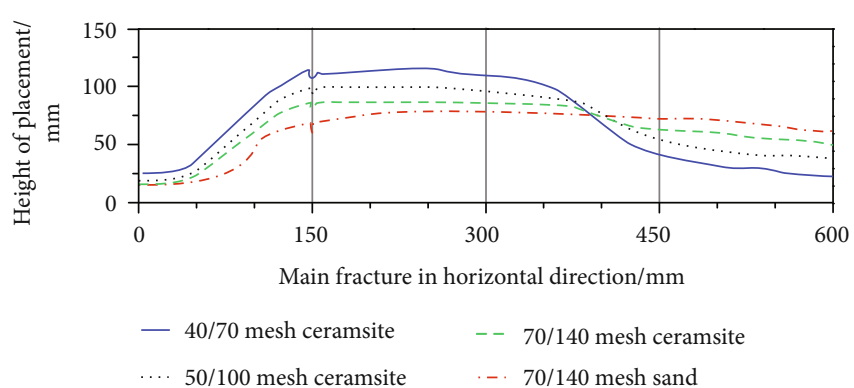

(a)

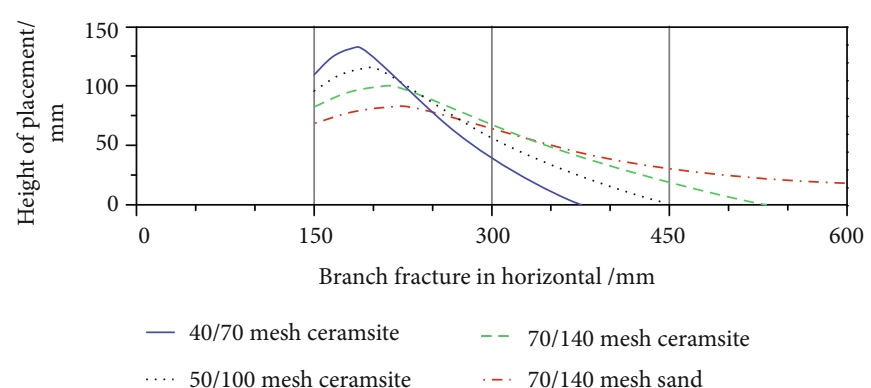

(b)

Figure 10: The transport characteristics of proppants in the main fracture (a) and branch fractures (b) with different proppant performances (granularity, density). 


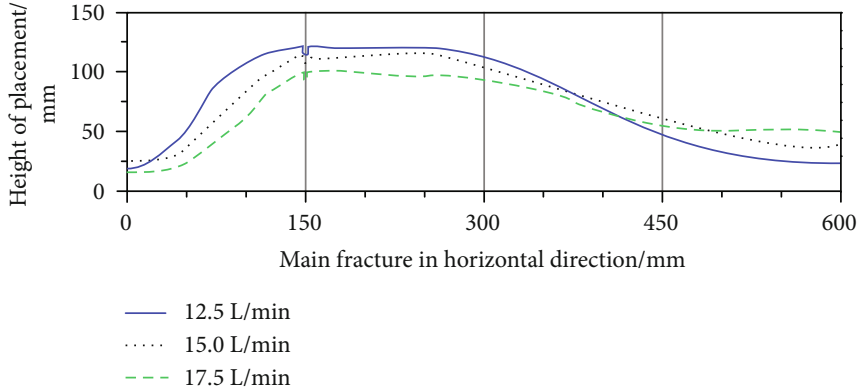

(a)

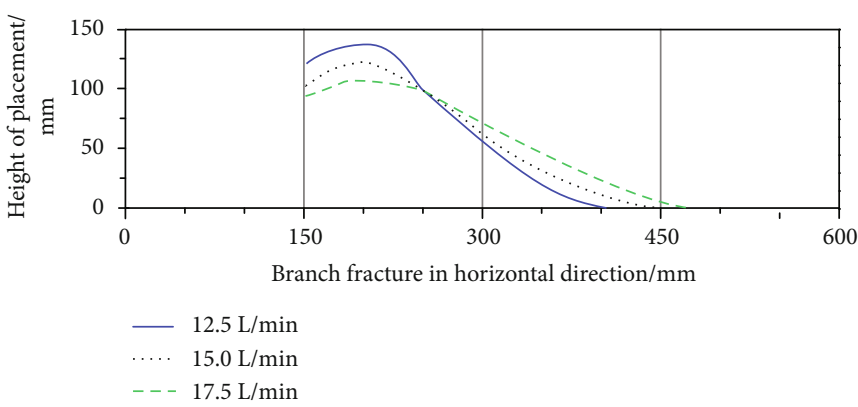

(b)

FIgURE 11: The transport characteristics of proppants in the main fracture (a) and branch fractures (b) with different displacements.

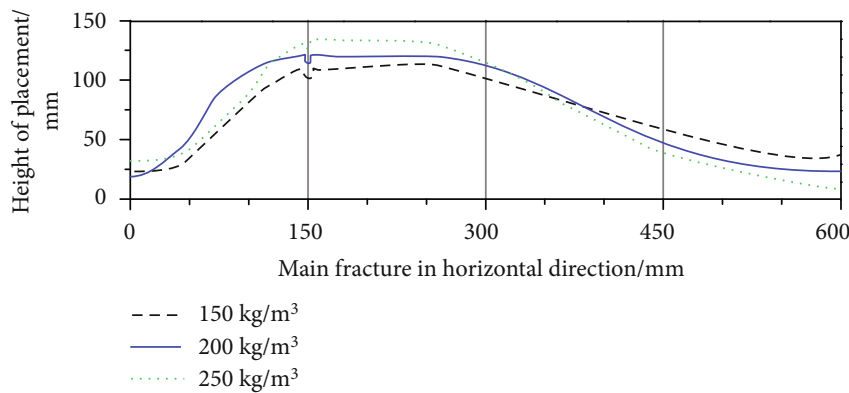

(a)

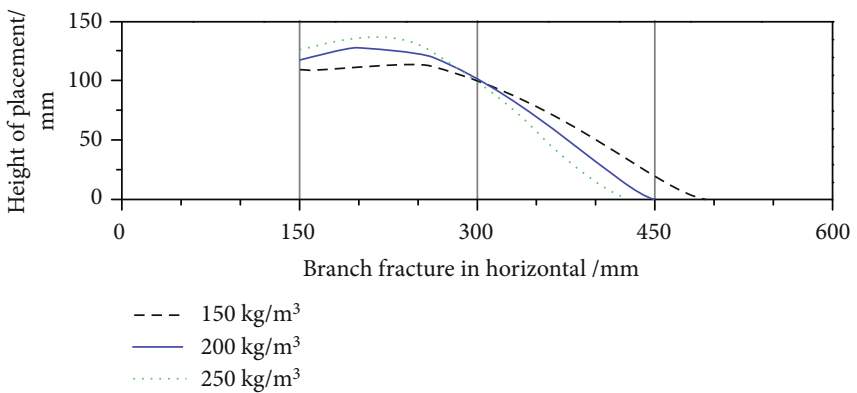

(b)

Figure 12: Proppant transport characteristics in the main fracture (a) and branch fractures (b) with different sand concentrations.

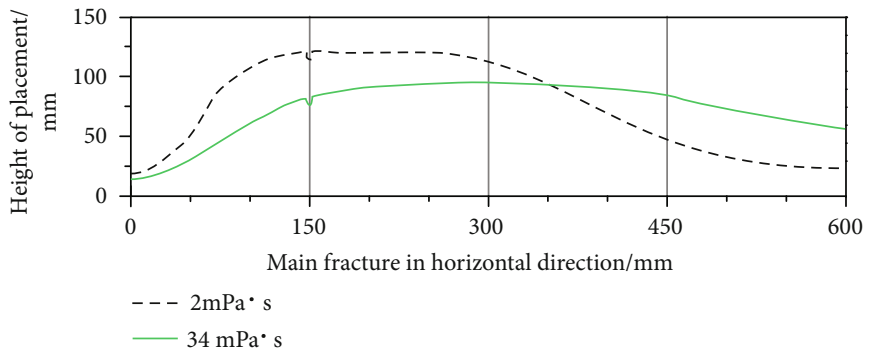

(a)

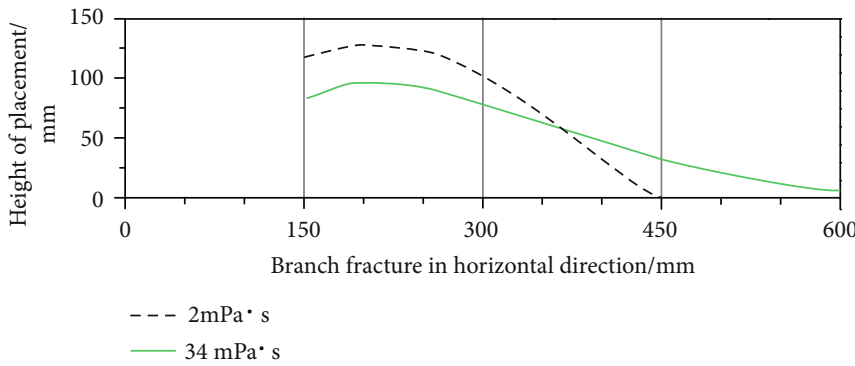

(b)

FIGURE 13: Proppant transport characteristics in the main fracture

the closer the diversion nodes, the smaller the fluid flow, the lower the flow velocity in the fractures, and the weaker the carrying and scouring effect of the proppant. Therefore, the farther away from the entrance of fractures, the higher the balanced heights of the proppant.

During the field operation, as the operation proceeds, the complexity of the fracture geometry increases, the fluid pump in the reservoir is diverted step by step, and the flow velocity in the branch fractures gradually decreases; meanwhile, the carrying capacity of the proppant and the scouring effect on the proppant dunes decrease. Therefore, the more complex the fractures are, the less conducive it is to the transport of the proppant. In the mid-term, high-displacement injection should be ensured to compensate the reduction in sand carrying capacity caused by the diversion of complex fractures and (a) and branch fractures (b) with different fracturing fluid viscosity.

enough proppants should be provided in branch fractures to improve the hydrocarbon production from the well.

\section{Sensitivity Analysis of Factors Affecting Proppant Transport Characteristics in Complex Fractures}

In order to understand the sensitivity of five factors to proppant transport characteristics in complex fractures, the sensitivity analysis method is applied to analyze and compare the sensitivities between them.

Sensitivity analysis is a method of analyzing system stability in system analysis. Given a system whose system characteristic $P$ is mainly determined by $n$ factors $a=\left\{a_{1}, a_{2}, \cdots, a_{n}\right\}$, 


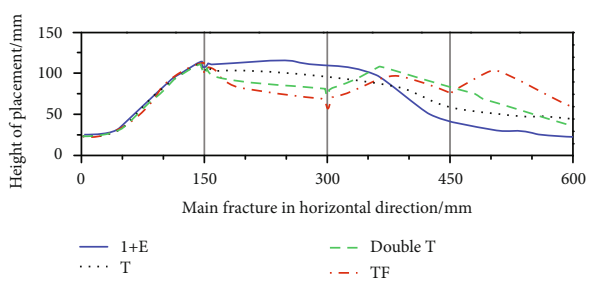

(a)

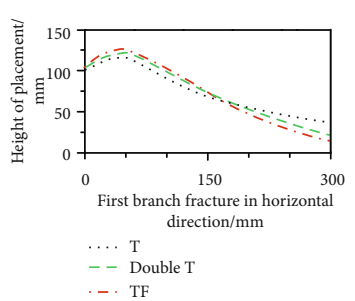

-. TF
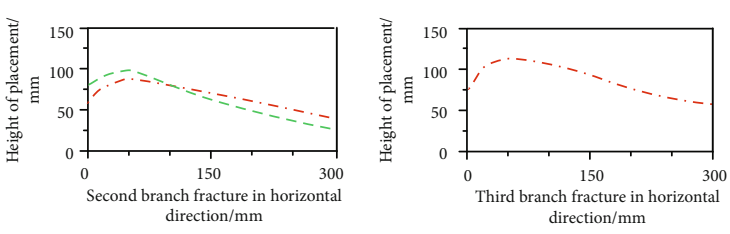

(b)

FIgURE 14: Proppant transport characteristics in the main fracture (a) and branch fractures (b) with different fracture geometry.

TABLE 3: Influencing factors and sensitivity factors of proppant transport characteristics in complex fractures.

\begin{tabular}{lccccc}
\hline Influencing factors & Proppant performance & Displacement & Sand concentration & Liquid viscosity & Fracture geometry \\
\hline Sensitivity factor & 1.19 & 0.91 & 0.71 & 1.07 & 1.35 \\
Sensitivity level & II & IV & V & III & I \\
\hline
\end{tabular}

$P=f\left(a_{1}, a_{2}, \cdots, a_{n}\right)$. In a certain reference state $a^{*}=\left\{a_{1}^{*}, a_{2}^{*}\right.$, $\left.\cdots, a_{n}^{*}\right\}$, the system characteristic is $P^{*}$. Make each factor changes within its own possible range, and analyse the trend and extent of the deviation of the system characteristic $P$ from the reference state $P^{*}$ caused by the changes of these factors, which is called sensitivity analysis [20].

When analyzing the influence of the $n$ parameter $a_{n}$ on the characteristic $P$, the other parameters are all referenced and the sensitivity of the system characteristic $P$ to $a_{n}$ is expressed as

$$
\psi\left(a_{k}\right)=f\left(a_{1}^{*}, a_{2}^{*}, \cdots, a_{k-1}^{*}, a_{k}^{*}, a_{k+1}^{*}, \cdots, a_{n}^{*}\right)
$$

where $\psi\left(a_{k}\right)$ is the sensitivity of the system characteristic $P$ to $a_{k}$.

The relative error of the system characteristic $P$ is

$$
\delta_{p}=\frac{|\Delta P|}{P}
$$

where $\Delta P$ is the sensitivity of the system characteristic $P$ to $a_{k}$.

The relative error of the parameter $a_{k}$ is

$$
\delta_{a_{k}}=\frac{\left|\Delta_{a_{k}}\right|}{a_{k}}
$$

where $\Delta_{a_{k}}$ is the error of $a_{k}$.

From formula (4), the sensitivity function curve $S_{k}-a_{k}$ of $a_{k}$ can be drawn. Take $a_{k}=a_{k}^{*}$ to get the sensitivity factor $S_{k}^{*}$ of the parameter $a_{k}$

$$
S_{k}^{*}=S_{k}\left(a_{k}^{*}\right)=\left|\left(\frac{d \varphi_{k}\left(a_{k}\right)}{d a_{k}}\right)_{a_{k}-a_{k}^{*}}\right| \frac{a_{k}^{*}}{P^{*}}, \quad k=1,2, \cdots, n .
$$

$S_{k}^{*}, k=1,2, \cdots, n$ is a set of dimensionless nonnegative real numbers. The larger the value of $S_{k}^{*}$, the more sensitive $P$ is to $a_{k}$ in the reference state. Through the comparison of $S_{k}^{*}$, the sensitivity of the system characteristics to various factors can be compared and evaluated.

System characteristics, the proppant transport characteristics in complex fractures, are characterized by the ratio of the balance height of the proppant to the proppant transport distance in the main and branch fractures. The parameters for sensitivity analysis include proppant performance, displacement, sand concentration, liquid viscosity, and fracture geometry.

Observe the proppant transport characteristics in complex fractures, and use curve fitting methods to obtain the sensitivity function, and then, calculate the sensitivity factor. Based on the existing experimental results and analysis, the sensitivity values of each parameters is obtained. As shown in Table 3, the sensitivity degree to proppant transport in order is fracture geometry, proppant performance, liquid viscosity, displacement, and proppant concentration.

\section{Conclusions}

(1) Discretize the disordered complex fractures to obtain an orthogonal three-dimensional complex fracture physical model. Develop a complex fracture experimental device, and form an experimental device to research the transport proppant in complex fractures. A highspeed video camera is used to record the proppant transport characteristics in the complex fracture during the entire experimental process under different conditions

(2) Complete experimental research with different factors on proppant transport characteristics in complex fractures. Results shows that, under different conditions (particle size, density, displacement, sand concentration, and liquid viscosity), the same proppant transport at the balance stage of the proppant dune is longer than that in the branch and the proppant dune has a relatively flat slope in the main fracture because liquid has a stronger scouring effect. 
With the fracture complexity increasing gradually and the fluid in fractures is diverted step by step, the later the diverging node, the lower the flow velocity in the fractures and the higher the balanced heights of the proppant

(3) Based on existing experimental results, observe the proppant transport characteristics in complex fractures and use curve fitting methods to establish the sensitivity function, and then, calculate the sensitivity factor of each influencing factors. Results show that the sensitivity degree to proppant transport in order is fracture geometry, proppant performance, liquid viscosity, displacement, and proppant concentration. The experimental device and research results can provide strong support to optimize the materials into wells and optimize field parameters for unconventional reservoirs multistaged horizontal well fracturing

\section{Data Availability}

The experimental data used to support the findings of this study are included within the article.

\section{Conflicts of Interest}

The authors declare that they have no conflicts of interest.

\section{References}

[1] Y. Peng, J. Zhao, K. Sepehrnoori, Z. Li, and F. Xu, "Study of delayed creep fracture initiation and propagation based on semi- analytical fractional model," Applied Mathematical Modelling, vol. 72, pp. 700-715, 2019.

[2] Y. Peng, J. Zhao, K. Sepehrnoori, and Z. Li, "Fractional model for simulating the viscoelastic behavior of artificial fracture in shale gas," Engineering Fracture Mechanics, vol. 228, p. 106892, 2020.

[3] N. R. Warpinski, M. J. Mayerhofer, M. C. Vincent, C. L. Cipolla, and E. P. Lolon, "Stimulation unconventional reservoirs: maximizing network growth while optimizing fracture conductivity," in 2008 SPE Unconventional Reservoirs Conference of SPE paper 114173, pp. 1-19, Keystone, Colorado, U.S.A., February 2008.

[4] G. E. King, "Thirty years of gas shale fracturing: what have we learned?" in Presented at SPE Annual Technical Conference and Exhibition of SPE paper 133456, pp. 88-90, Florence, Italy, September 2010.

[5] D. W. Weng, Q. Lei, Y. Xu, Y. Li, D. Q. Li, and W. X. Wang, "Network fracturing techniques and its application in the field," Acta Petrolei Sinica, vol. 32, no. 2, pp. 280-284, 2011.

[6] C. Zou, R. Zhu, K. Liu et al., "Tight gas sandstone reservoirs in China: characteristics and recognition criteria," Journal of Petroleum Science and Engineering, vol. 88-89, pp. 82-91, 2012.

[7] S. A. Holditch, “Tight gas sands," Journal of Petroleum Technology, vol. 58, no. 6, pp. 86-93, 2006.

[8] M. M. Hossain and M. K. Rahman, "Numerical simulation of complex fracture growth during tight reservoir stimulation by hydraulic fracturing," Journal of Petroleum Science and Engineering, vol. 60, no. 2, pp. 86-104, 2008.
[9] E. J. House, "Fractured fairytales: the failed social license for unconventional oil and gas development," Wyoming Law Review, vol. 13, pp. 6-67, 2013.

[10] J. D. McLennan, S. J. Green, and M. Bai, “Proppant placement during tight gas shale stimulation: literature review and speculation," in Presented at the 42th US Rock Mechanics Symposium and 2nd US-Canada Rock Mechanics Symposium of ARMA paper 08-355, pp. 1-14, San Francisco, June-July 2008.

[11] N. Li, J. Li, L. Zhao, Z. Luo, P. Liu, and Y. Guo, "Laboratory testing and numeric simulation on laws of proppant transport in complex fracture systems," in Presented at SPE Asia Pacific Hydraulic Fracture Conference of SPE paper181822, pp. 1-16, Beijing, China, August 2016.

[12] Y. Liu and M. M. Sharma, "Effect of fracture width and fluid rheology on proppant settling and retardation: an experimental study," in Presented at the SPE Annual Technical Conference and Exhibition of SPE paper 96208, pp. 1-12, Dallas, Texas, USA, October 2005.

[13] R. Sahai, Laboratory Evaluation of Proppant Transport in Complex Fracture Systems, [M.S. Thesis], Colorado School of Mines, Golden, Colorado, 2012.

[14] Q. Wen, S. Wang, X. Duan, Y. Li, F. Wang, and X. Jin, "Experimental investigation of proppant settling in complex hydraulic-natural fracture system in shale reservoirs," Journal of Natural Gas Science and Engineering, vol. 33, no. 2016, pp. 70-80, 2016.

[15] M. A. Alotaibi and J. L. Miskimins, "Slickwater proppant transport in hydraulic fractures: new experimental findings and scalable correlation," in Presented at SPE Annual Technical Conference and Exhibition of SPE Paper 174828-PA, pp. 164-178, Houston, TX, September 2015.

[16] A. Dayan, S. M. Stracener, and P. E. Clark, "Proppant transport in slickwater fracturing of shale gas formations," in SPE annual technical conference and exhibition, pp. 56-59, 2009.

[17] T. T. Palisch, M. Vincent, and P. J. Handren, "Slickwater fracturing: food for thought," SPE Production \& Operations, vol. 25, no. 3, pp. 327-344, 2010.

[18] R. Barati and J. T. Liang, "A review of fracturing fluid systems used for hydraulic fracturing of oil and gas wells," Journal of Applied Polymer Science, vol. 131, no. 16, 2014.

[19] N. H. Kostenuk and D. J. Browne, "Improved proppant transport system for slickwater shale fracturing," in Paper presented at the Canadian Unconventional Resources and International Petroleum Conference, pp. 1-10, Calgary, Alberta, Canada, 2010.

[20] Z. Guang and Z. Weishen, "Parameter sensitivity analysis and optimizing for test programs," Rock and Soil Mechanics, vol. 14, no. 1, pp. 51-57, 1993.

[21] Y. Peng, Y. Li, and J. Zhao, "A novel approach to simulate the stress and displacement fields induced by hydraulic fractures under arbitrarily distributed inner pressure," Journal of Natural Gas Science and Engineering, vol. 35, pp. 1079-1087, 2016.

[22] J. Zhao, Y. L. Peng, Y. Li, and W. Xiao, “Analytical model for simulating and analyzing the influence of interfacial slip on fracture height propagation in shale gas layers," Environmental Earth Sciences, vol. 73, no. 10, pp. 5867-5875, 2015. 